\title{
Clinical profile of 550 cases of surgical and natural menopause
}

\author{
Mahjabeen $\mathrm{N}^{\mathrm{a}}$, Nasreen SZA ${ }^{\mathrm{b}}$
}

\begin{abstract}
Background: Menopause represents the permanent cessation of menstrual periods and the loss of fertility due to the loss of ovarian function. It can occur spontaneously (natural menopause) or it can be surgically induced. They are different entirely. One is a natural stage of life that all women experience, the other is the result of surgery, that is, bilateral oophorectomy. Surgical menopause is when surgery, rather than the natural aging process, causes a woman to go through menopause. The ovaries are the main source of estrogen production in the female body. Their removal triggers immediate menopause, despite the age of the person having surgery. While surgery to remove the ovaries can operate as a stand-alone procedure, it is sometimes performed in addition to hysterectomy to reduce the risk of developing chronic diseases. This study was designed to compare the effects of the natural and the surgical menopause.
\end{abstract}

Methods: This prospective observational study was conducted in the Department of Obstetrics and Gynaecology of Z. H. Sikder Women's Medical College \& Hospital, Dhaka from January 2016 to December 2018. During the study period a total of 275 patients with surgical menopause (total abdominal hysterectomy with bilateral salpingo-oophorectomy was done in all cases) and 275 patients with natural menopause were enrolled. After taking written consent detailed information about the patients was collected in a predesigned data collection sheet for each patient.

Results: Age of most of the patients in surgical menopause group was within 41 to 50 years and most patients were $>50$ years old in natural menopause group. Most of the patients were illiterate in both groups and maximum patients were in poor socio-economic condition in both groups. Hot flush (48.0\% vs 28.0\%), palpitation (28.0\% vs 4.0\%) and dryness of vagina (12.0\% vs $0.0 \%)$ were higher and body ache (32.0\% vs 48.0\%), tiredness $(8.0 \%$ vs $36.0 \%)$, insomnia $(8.0 \%$ vs $28.0 \%)$, depression (4.0\% vs 16.0\%), lack of concentration $(0.0 \%$ vs $4.0 \%)$, loss of memory (0.0\% vs $16.0 \%)$ and irritability $(4.0 \%$ vs $8.0 \%)$ were found significantly lower in surgical menopause than natural menopause group. Dyspareunia (72.0\% vs 28.0\%), dysuria (92.0\% vs $40.0 \%$ ) and increased frequency of urination (68.0\% vs 36.0\%) were significantly higher in surgical menopause than natural menopause group. Urgency, hesitancy and incontinence of urination were significantly lower in surgical menopause than natural menopause group.

Conclusion: Ovaries were removed in all of the surgical menopause cases, which may be the reason of more deleterious effects in surgical menopause than natural menopause. So, it is highly recommended to preserve ovaries in hysterectomies due to benign indications.

Keywords: Surgical menopause, natural menopause.

(BIRDEM Med J 2020; 10(3): 168-171)

\section{Author information}

a. Nusrat Mahjabeen, Assistant Professor, Department of Obs. \& Gynae, Z.H. Sikder Women's Medical College \& Hospital, Dhaka.

b. Shaikh Zinnat Ara Nasreen, Professor \& Head of Department of Obs. \& Gynae, Z.H. Sikder Women's Medical College \& Hospital, Dhaka.

Address of correspondence: Dr. Nusrat Mahjabeen, Assistant Professor, Department of Obs. \& Gynae, Z.H. Sikder Women's Medical College \& Hospital, Dhaka. Email: nusrat.bonny63 @gmail.com

Received: October 31, 2019

Accepted: June 30, 2020

\section{Introduction}

Menopause is the permanent cessation of menstruation resulting from reduced ovarian hormone secretion that occurs either naturally or is induced by surgery, chemotherapy or radiation. Natural menopause can be recognized after 12 months of amenorrhea that is not associated with a pathologic cause. ${ }^{1}$ Surgical menopause is the cessation of menses resulting from surgical removal of the uterus, leaving one or both ovaries or the removal of both ovaries. ${ }^{2}$ 
The genitourinary syndrome of menopause (GSM) is a new term that describes various menopausal symptoms and signs associated with physical changes of the vulva, vagina and lower urinary tract. The GSM includes not only genital symptoms (dryness, burning and irritation) and sexual symptoms (lack of lubrication, discomfort or pain and impaired function), but also urinary symptoms (urgency, dysuria and recurrent urinary tract infections). ${ }^{3}$

The syndrome or its features manifest in some manner in approximately $15 \%$ of premenopausal women ${ }^{4}$ and $40-54 \%$ of postmenopausal women. ${ }^{5}$ Because women have a higher life expectancy than men and approximately $>17 \%$ of the population will be age $>65$ years by 2030 , the consequences of declined endogenous estrogen levels in menopausal women should be of great interest to clinicians. ${ }^{6}$

In Western women, $45 \%$ to $63 \%$ of postmenopausal women reported that they had experienced vulvovaginal symptoms ${ }^{7}$ most commonly vaginal dryness; other symptoms included dyspareunia, vaginal irritation, itching sensation, vaginal tenderness and vaginal bleeding or spotting during intercourse. ${ }^{7-9}$ Similarly, in a Korean study, $49 \%$ of postmenopausal women had experienced vulvovaginal symptoms including vaginal dryness and dyspareunia. ${ }^{10}$

As a result of estrogen deficiency after menopause, anatomic and histologic changes occur in female genital tissues, including reduction in the content of collagen and hyaluronic acid and in the levels of elastin, thinning of the epithelium, alterations in the function of smooth muscle cells, increase in the density of connective tissue and fewer blood vessels. These changes reduce elasticity of the vagina, increase vaginal $\mathrm{pH}$, lead to changes in vaginal flora, diminish lubrication and increase vulnerability to physical irritation and trauma. ${ }^{11,12}$

The female genital tract and lower urinary tract share a common embryonic origin, both arising from the urogenital sinus. As estrogen plays an important role in the function of the lower urinary tract throughout the premenopausal period, estrogen deficiency after menopause causes lower urinary tract symptoms, such as dysuria, urgency, frequency, nocturia, urinary incontinence (UI) and recurrent UTI. ${ }^{13}$

In a study by Robinson and Cardozo ${ }^{13}$ about $20 \%$ of postmenopausal women had severe urgency and almost
$50 \%$ had stress incontinence. In particular, urge incontinence is more prevalent after menopause than before menopause and its prevalence increases with time in women with estrogen deficiency. The study by Hyun et al. ${ }^{14}$ suggested that the major cause of UI in postmenopausal women was the intrinsic sphincteric dysfunction related to altered connective tissue following estrogen deficiency, while the anatomical change was the most responsible factor of UI in premenopausal women. The incidence of UTI rises dramatically in elderly women. Studies have shown that $15 \%$ to $20 \%$ of women aged 65 to 70 years and $20 \%$ to $50 \%$ of women aged $>80$ years have bacteriuria. ${ }^{15,16}$

This study was aimed to identify symptoms toward menopause in a definite age grouped women and the profound negative impact on QOL (Quality of life) of postmenopausal women. Women should be made aware of their problems and treated with an appropriate effective therapy. The fundamental data of women's symptoms could be a strategy to guide the management for encouraging a successful menopausal transition in postmenopausal women.

\section{Methods}

This prospective observational study was conducted in the Department of Obstetrics and Gynaecology of Z.H. Sikder Women's Medical College \& Hospital, Dhaka from January 2016 to December 2018. During the study period a total of 550 patients were enrolled ( 275 cases of surgical menopause and 275 cases of natural menopause). After taking written consent detailed information about the patients was collected in a predesigned data collection sheet for each patient.

\section{Inclusion criteria}

- Age: 41-75 years

- Surgical menopause: all patients underwent total abdominal hysterectomy with bilateral salpingooophorectomy

- Surgery was done for benign causes

\section{Exclusion criteria}

- Associated chronic liver disease and neurological disorders

- Malignant cases 


\section{Results}

Age of most of the patients in surgical menopause group was within 41 to 50 years and most patients were $>50$ years old in natural menopause group. Most of the patients were illiterate in both groups and maximum patients were in poor socio-economic condition in both groups (Table I).

Table I Demographic profile of the study subjects in surgical and normal menopause groups $(\mathrm{N}=550)$

\begin{tabular}{lccc}
\hline & $\begin{array}{c}\text { Surgical } \\
\text { menopause } \\
(\mathrm{n}=275)\end{array}$ & $\begin{array}{c}\text { Natural } \\
\text { menopause } \\
(\mathrm{n}=275)\end{array}$ & $\begin{array}{c}\mathrm{p} \text { - } \\
\text { value }\end{array}$ \\
\hline Age (years) & $209(76.0)$ & $88(32.0)$ & $<0.001$ \\
$41-50$ & $44(16.0)$ & $99(36.0)$ & \\
$51-60$ & $22(8.0)$ & $77(28.0)$ & \\
$61-70$ & $0(0.0)$ & $11(4.0)$ & \\
$>70$ & $48.32 \pm 7.15$ & $56.96 \pm 8.91$ & \\
Mean \pm SD & & & \\
Education & $187(68.0)$ & $176(64.0)$ & $<0.001$ \\
Illiterate & $66(24.0)$ & $66(24.0)$ & \\
Primary & $11(4.0)$ & $0(0.0)$ & \\
HSC & $11(4.0)$ & $33(12.0)$ & \\
Higher & & & \\
Socio-economic status & & \\
Low & $165(60.0)$ & $154(56.0)$ & $<0.001$ \\
Lower middle & $99(36.0)$ & $77(28.0)$ & \\
Upper middle & $11(4.0)$ & $11(4.0)$ & \\
High & $0(0.0)$ & $33(12.0)$ & \\
\hline & & &
\end{tabular}

Hot flush (48.0\% vs $28.0 \%$ ), palpitation (28.0\% vs $4.0 \%)$ and dryness of vagina $(12.0 \%$ vs $0.0 \%)$ were higher and body ache (32.0\% vs $48.0 \%)$, tiredness $(8.0 \%$ vs $36.0 \%)$, insomnia $(8.0 \%$ vs $28.0 \%)$, depression ( $4.0 \%$ vs $16.0 \%)$, lack of concentration $(0.0 \%$ vs $4.0 \%)$, loss of memory $(0.0 \%$ vs $16.0 \%)$ and irritability $(4.0 \%$ vs $8.0 \%)$ were found significantly lower in surgical menopause than natural menopause group. Dyspareunia (72.0\% vs $28.0 \%$ ), dysuria $(92.0 \%$ vs $40.0 \%)$ and increased frequency of urination $(68.0 \%$ vs $36.0 \%$ ) were significantly higher in surgical menopause than natural menopause group. Urgency, hesitancy and incontinence of urination were significantly lower in surgical menopause than natural menopause group (Table II).
Table II Complaints of the study subjects in surgical and normal menopause groups $(\mathrm{N}=550)$

\begin{tabular}{|c|c|c|c|}
\hline & $\begin{array}{c}\text { Surgical } \\
\text { menopause } \\
(\mathrm{n}=275)\end{array}$ & $\begin{array}{c}\text { Natural } \\
\text { menopause } \\
(\mathrm{n}=275)\end{array}$ & $\begin{array}{c}\text { p- } \\
\text { value }\end{array}$ \\
\hline Hot flush & $132(48.0)$ & $77(28.0)$ & $<0.001$ \\
\hline Palpitation & $77(28.0)$ & $11(4.0)$ & $<0.001$ \\
\hline Dryness of vagina & $33(12.0)$ & $0(0.0)$ & $<0.001$ \\
\hline Body ache & $88(32.0)$ & $132(48.0)$ & $<0.001$ \\
\hline Tiredness & $22(8.0)$ & $99(36.0)$ & $<0.001$ \\
\hline Insomnia & $22(8.0)$ & $77(28.0)$ & $<0.001$ \\
\hline Depression & $11(4.0)$ & $44(16.0)$ & $<0.001$ \\
\hline Lack of concentration & $0(0.0)$ & $11(4.0)$ & 0.001 \\
\hline Loss of memory & $0(0.0)$ & $44(16.0)$ & $<0.001$ \\
\hline Irritability & $11(4.0)$ & $22(8.0)$ & 0.048 \\
\hline Dyspareunia & $198(72.0)$ & $77(28.0)$ & $<0.001$ \\
\hline \multicolumn{4}{|l|}{ Urinary complaints } \\
\hline Dysuria & $253(92.0)$ & $110(40.0)$ & $<0.001$ \\
\hline Increased frequency & $187(68.0)$ & $99(36.0)$ & $<0.001$ \\
\hline Incomplete evacuation & $110(40.0)$ & $110(40.0)$ & 1.000 \\
\hline Urgency & $0(0.0)$ & $33(12.0)$ & $<0.001$ \\
\hline Hesitancy & $11(4.0)$ & $33(12.0)$ & 0.001 \\
\hline Incontinence & $0(0.0)$ & $44(16.0)$ & $<0.001$ \\
\hline
\end{tabular}

*Multiple responses

\section{Discussion}

In this study mean age was $48.32 \pm 7.15$ years in surgical menopause and $56.96 \pm 8.91$ years in natural menopause patients. Age of the natural menopause patients was significantly higher than surgical menopause patients. In the study of Mahajanet al. ${ }^{17}$ and Ozdemir et al. ${ }^{18}$, there were no significant difference in age between surgical menopause and natural menopause patients.

During menopause women experience numerous bothersome symptoms like hot flushes, sweating, poor memory and decreased libido as well as decrease BMD and some metabolic changes. In this study, hot flush ( $48.0 \%$ vs $28.0 \%$ ), palpitation ( $28.0 \%$ vs $4.0 \%$ ), dryness of vagina $(12.0 \%$ vs $0.0 \%)$ were found significantly higher in surgical menopause than natural menopause. But body ache $(32.0 \%$ vs $48.0 \%)$, tiredness $(8.0 \%$ vs $36.0 \%$ ), insomnia $(8.0 \%$ vs $28.0 \%)$, depression $(4.0 \%$ vs $16.0 \%)$, lack of concentration $(0.0 \%$ vs $4.0 \%)$, loss of memory $(0.0 \%$ vs $16.0 \%)$ and irritability $(4.0 \%$ vs $8.0 \%$ ) were found significantly lower in surgical menopause than natural menopause. Nasreen et al. ${ }^{19}$ found significantly higher incidence of hot flush, feeling 
depression and loss of memory in surgical menopause. Similarly, Ozdemir et al. ${ }^{18}$ found significantly higher incidence of hot flushes, sweating, poor memory and change in sexual desire in surgical menopause.

Duffy et al. ${ }^{20}$ also stated that higher proportion of surgically menopause women experience the extremely bothersome symptoms than naturally menopause women. Incidence of dyspareunia was significantly higher in surgically menopause women than naturally menopause women. Similarly, incidence of urinary complains (dysuria and increased frequency) were found significantly higher in surgically menopause women than naturally menopause women. Similar to this study, urinary complaints were found more in surgical menopause than natural menopause even though not statistically significant. ${ }^{18}$

Hesitancy was found significantly less in surgical menopause than natural menopause in this study. Almost similar finding was seen in the study of Ozdemir et al. ${ }^{18}$

\section{Limitations of the study and recommendation}

The study was single center based with limited study population. So, multi-center study is recommended in the future.

\section{Conclusion}

In all of the surgical menopause cases, ovaries were sacrificed. And this may be the reason of more deleterious effects in surgical menopause than natural menopause. So, it is highly recommended to preserve ovaries in hysterectomies due to benign indications.

Conflict of interest: Nothing to declare.

\section{References}

1. Rahman SA, Zainudin SR, Mun VL. Assessment of menopausal symptoms using modified menopause rating scale (MRS) among middle age women in Kuching, Sarawak, Malaysia. Asia Pac Fam Med 2010;9:5.

2. Brett KM. Can hysterectomy be considered a risk factor for cardiovascular disease? Circulation 2005;111:1456-58.

3. Portman DJ, Gass ML, Vulvovaginal Atrophy Terminology Consensus Conference Panel. Genitourinary syndrome of menopause: new terminology for vulvovaginal atrophy from the International Society for the Study of Women's Sexual Health and the North American Menopause Society. Climacteric 2014 Oct 1;17(5):557-63.

4. Palacios S. Managing urogenital atrophy. Maturitas 2009 Aug 20;63(4): 315-18.

5. DiBonaventura M, Luo X, Moffatt M, Bushmakin AG, Kumar M, Bobula J. The association between vulvovaginal atrophy symptoms and quality of life among postmenopausal women in the United States and Western Europe. J Womens Health (Larchmt) 2015;24: 713-22.

6. Keil K. Urogenital atrophy: diagnosis, sequelae, and management. Curr Womens Health Rep 2002;2:305-11.

7. Nappi RE, Kokot-Kierepa M. Women's voices in the menopause: results from an international survey on vaginal atrophy. Maturitas 2010; 67: 233-38.

8. Nappi RE, Kokot-Kierepa M. Vaginal Health: Insights, Views \& Attitudes (VIVA) - results from an international survey. Climacteric 2012; 15: 36-44.

9. Kingsberg SA, Wysocki S, Magnus L, Krychman ML. Vulvar and vaginal atrophy in postmenopausal women: findings from the REVIVE (REal Women's VIews of Treatment Options for Menopausal Vaginal ChangEs) survey. J Sex Med 2013; 10: 1790-99.

10. Chae HD, Choi SY, Cho EJ, Cho YM, Lee SR, Lee ES, et al. Awareness and experience of menopausal symptom and hormone therapy in korean postmenopausal women. J Menopausal Med 2014; 20: 7-13.

11. Nappi RE, Palacios S. Impact of vulvovaginal atrophy on sexual health and quality of life at postmenopause. Climacteric 2014; 17: 3-9.

12. Tan O, Bradshaw K, Carr BR. Management of vulvovaginal atrophy-related sexual dysfunction in postmenopausal women: an up-to-date review. Menopause 2012; 19: 109-17.

13. Robinson D, Cardozo LD. The role of estrogens in female lower urinary tract dysfunction. Urology 2003; 62: 45-51.

14. Hyun HS, Park BR, Kim YS, Mun ST, Bae DH. Urodynamic characterization of postmenopausal women with stress urinary incontinence: retrospective study in incontinent pre- and postmenopausal women. J Korean Soc Menopause 2010; 16: 14852.

15. Brown JS, Vittinghoff E, Kanaya AM, Agarwal SK, Hulley S, Foxman B. Urinary tract infections in postmenopausal women: effect of hormone therapy and risk factors. ObstetGynecol 2001; 98: 1045-52.

16. Raz R. Urinary tract infection in postmenopausal women. Korean J Urol 2011; 52: 801-8. Palacios S. Managing urogenital atrophy. Maturitas 2009;63:315-18.

17. Mahajan N, Kumar D, Fareed P. Comparison of Menopausal Symptoms and Quality of Life after Natural and Surgical Menopause. International Journal of Scientific Study 2016 Feb 1;3(11):74-77.

18. Özdemir S, Çelik Ç, Görkemli H, Kýyýcý A, Kaya B. Compared effects of surgical and natural menopause on climacteric symptoms, osteoporosis, and metabolic syndrome. International Journal of Gynecology \& Obstetrics 2009 Jul 1;106(1):57-61.

19. Nasreen SZA, Shahreen S, Rahman S. Comparison between surgical and normal menopause in genitourinary syndrome of menopause (GSM)? J South Asian Feder Menopause Coc 2013; 1(2): 63-65.

20. Duffy OK, Iversen L, Hannaford PC. The impact and management of symptoms experienced at midlife: a community based study of women in northeast Scotland. BJOG: An International Journal of Obstetrics \& Gynaecology 2012 Apr;119(5):554-64. 